\title{
Deriving clear-sky longwave spectral flux from spaceborne hyperspectral radiance measurements: a case study with AIRS observations
}

\author{
Xiuhong Chen and Xianglei Huang \\ Department of Climate and Space Sciences and Engineering, University of Michigan, Ann Arbor, MI 48109, USA \\ Correspondence to: Xiuhong Chen (xiuchen@umich.edu)
}

Received: 12 August 2016 - Published in Atmos. Meas. Tech. Discuss.: 7 September 2016

Revised: 18 November 2016 - Accepted: 21 November - Published: 14 December 2016

\begin{abstract}
Previous studies have shown that longwave (LW) spectral fluxes have unique merit in climate studies. Using Atmospheric Infrared Sounder (AIRS) radiances as a case study, this study presents an algorithm to derive the entire LW clear-sky spectral fluxes from spaceborne hyperspectral observations. No other auxiliary observations are needed in the algorithm. A clear-sky scene is identified using a threestep detection method. The identified clear-sky scenes are then categorized into different sub-scene types using information about precipitable water, lapse rate and surface temperature inferred from the AIRS radiances at six selected channels. A previously established algorithm is then used to invert AIRS radiances to spectral fluxes over the entire LW spectrum at $10 \mathrm{~cm}^{-1}$ spectral interval. Accuracy of the algorithms is evaluated against collocated Clouds and the Earth's Radiant Energy System (CERES) observations. For nadir-view observations, the mean difference between outgoing longwave radiation (OLR) derived by this algorithm and the collocated CERES OLR is $1.52 \mathrm{Wm}^{-2}$ with a standard deviation of $2.46 \mathrm{Wm}^{-2}$. When the algorithm is extended for viewing zenith angle up to $45^{\circ}$, the performance is comparable to that for nadir-view results.
\end{abstract}

\section{Introduction}

Broadband outgoing longwave radiation (OLR) obtained by the Earth Radiation Budget Experiment (ERBE; Barkstrom, 1984) and Clouds and the Earth's Radiant Energy System (CERES; Wielicki et al., 1996) has been extensively used in climate studies for 3 decades. The physical quantity directly measured by the ERBE or CERES instruments is ac- tually a convolution between broadband upwelling radiance at a given viewing zenith angle (VZA) and the spectral response function (SRF) of the broadband radiometer on the ERBE or CERES. Then the broadband upwelling radiance is inferred through deconvolution of the measurement, and, subsequently, it is converted to broadband flux (e.g., Loeb et al., 2005; Kato and Loeb, 2005). In order to reliably derive the broadband flux, a variety of auxiliary information needs to be used to define the scene type for each instrument footprint. Such auxiliary information includes, but is not limited to, surface temperature, lapse rate, precipitable water and cloud macroscopic properties (e.g., cloud fraction, cloud emissivity). For the case of CERES, such auxiliary information is obtained from other satellite measurements such as the Moderate Resolution Imaging Spectroradiometer (MODIS) and Special Sensor Microwave Imager (SSM/I) as well as operational analysis (Loeb et al., 2005).

The integrand of broadband OLR, the spectral flux, is not available from the broadband flux measurements such as ERBE or CERES because of the nature of broadband radiometer in these measurements. However, the spectral flux can provide critically valuable information for the climate model diagnostics. In particular, comparing modeled and observed spectral flux can expose compensating biases in the simulated radiation budget by the climate model that otherwise cannot be exposed from broadband flux diagnostics alone (Huang et al., 2006, 2013, 2014). Similarly, spectral cloud radiative forcing can also help expose compensating biases from different bands (Huang et al., 2013, 2014).

Currently there are several operational hyperspectral sounders in space that measure spectral radiances in thousands of infrared (IR) channels, for example, Atmospheric 
Infrared Sounder (AIRS; Aumann et al., 2003) since 2002, Infrared Atmospheric Sounding Interferometer (IASI; Hilton et al., 2012) since 2006 and Cross-track Infrared Sounder (CrIS; Han et al., 2013; Strow et al., 2013) since 2011. Each of these sounders can acquire several million spectra per day. A series of studies published in recent years (Huang et al., 2008, 2010, 2014; Chen et al., 2013) have established algorithms to estimate observation-based spectral flux from the AIRS radiances using the scene type information from collocated CERES footprints. Specifically, spectral angular distribution models (ADMs) for each AIRS channel have been constructed for the scene types defined for the CERES SSF (single-satellite footprint) data set and then applied to AIRS radiances to derive spectral flux at each AIRS channel. The spectral ADMs are trained from synthetic AIRS radiances, and the meteorological fields from the ECMWF ERAInterim reanalysis (Dee et al., 2011) that are used to generate the synthetic radiances. A principal component-based multivariate linear regression scheme is then used to estimate spectral flux over the spectral bands not covered by the AIRS instrument. The end product is spectral flux at $10 \mathrm{~cm}^{-1}$ interval over the entire longwave (LW) spectrum. The spectral flux derived from this method has been extensively compared with the collocated CERES OLR, and the agreement is robustly consistent across different scene types and over different spatial and temporal scales, from footprint level to gridded data, and from monthly means to annual means and interannual variations (Huang et al., 2008, 2010, 2014; Chen et al., 2013).

The aforementioned series of studies took a shortcut by relying on the scene type information from the collocated CERES data set. The other hyperspectral sounders such as CrIS and IASI also fly with imagers such as the Visible Infrared Imaging Radiometer Suite (VIIRS) and Advanced Very High Resolution Radiometer (AVHRR), respectively. These imagers provide information needed for scene type classification. However, to apply information from these imagers, the near-simultaneous observations as well as the collocation strategy are required to overcome the differences in observational area and time period (Huang et al., 2008; O'Carroll et al., 2012; Wang et al., 2013). The rich information contained in the hyperspectral radiances naturally leads to a hypothesis that all information needed for defining scene types might be already contained in the spectral radiances. Therefore, a scientifically intriguing question to ask is, can we directly estimate spectral flux from such observations of hyperspectral radiances without relying on auxiliary observations and thus avoid the trouble of collocation strategy and reduction of samples? To follow this line of thinking, this study explores ways of defining scene types and sub-scene types from hyperspectral measurements such as AIRS radiances, and then evaluates the spectral flux derived in this manner. As a first step, this study focuses on clear-sky scene types; i.e., only non-cloud parameters (precipitable water, lapse rate and surface temperature) are con- sidered in the definition of sub-scene types. This effort aims to estimate longwave spectral flux and broadband OLR directly from AIRS Level 1 calibrated radiances over each individual single footprint. This approach is different from other studies such as Dessler et al. (2008), Moy et al. (2010) and Susskind et al. (2012), which fed temperature and humidity fields from AIRS Level 2 retrievals (defined for threeby-three AIRS footprints) or even the Level 3 monthly gridded data set into a radiative transfer model to compute the clear-sky OLR. Huang et al. (2008, 2010, 2014) and Chen et al. (2013) have demonstrated that such direct estimate of spectral flux from AIRS radiances is feasible, and the estimated OLR highly agree with the collocated CERES OLR. Furthermore, the merit of the spectral flux in testing climate models also warrants a feasibility study of deriving spectral flux (preferably over the entire longwave spectrum) from the hyperspectral satellite observations. All these facts have motivated the study presented in this article.

The rest of this paper is organized as follows. Section 2 describes the data set and forward model used in this study. Clear-sky detection, sub-scene type classification and the derivation of spectral flux for the case of nadir-view observations are described in Sect. 3. Section 4 validates the overall algorithm mentioned in Sect. 3. Section 5 discusses performances of the algorithm in other viewing zenith angles within $\pm 45^{\circ}$. Conclusions and further discussion are then presented in Sect. 6.

\section{Data sets and forward model}

The data sets and forward model used in this study are identical to those used in Huang et al. (2008) and Chen et al. (2013). Below is a brief depiction of the relevant features of the data and forward model.

AIRS is an infrared grating array spectrometer aboard NASA's Aqua satellite launched in 2002 (Aumann et al., 2003). It measures radiances across three bands - 2181.5$2665.2,1217.0-1613.9$ and $649.6-1136.6 \mathrm{~cm}^{-1}$ - with a spectral resolving power $(\lambda / \Delta \lambda)$ of $\sim 1200$, which converts to approximate full width at half maximum (FWHM) resolutions of $\sim 0.5 \mathrm{~cm}^{-1}$ at $650 \mathrm{~cm}^{-1}$ and $\sim 2.0 \mathrm{~cm}^{-1}$ at $2500 \mathrm{~cm}^{-1}$. The near-IR band is not used to derive spectral fluxes over $10-2000 \mathrm{~cm}^{-1}$. It scans from -49 to $49^{\circ}$ across the track with $13.5 \mathrm{~km}$ ground footprints at the nadir view. This study uses AIRS Level 1B calibrated radiances in the entire year of 2004.

For the purpose of validation, broadband OLR and subscene type information from the Aqua CERES SSF Edition 3 are used. The strategy to collocate CERES and AIRS observations at the footprint level is the same as described in Huang et al. (2008). CERES nadir-view field of view (FOV) is $\sim 20 \mathrm{~km}$ at the surface. The CERES SSF algorithm employs a MODIS-imagery-based algorithm to detect clear-sky footprints (Geier et al., 2003). A CERES field of view is clas- 
sified as a clear-sky scene if the coincident MODIS pixellevel cloud coverage within the FOV is less than $0.1 \%$. The total precipitable water (TPW) in the CERES SSF data set is retrieved from the SSM/I (Goodberlet et al., 1990). Its lapse rate $(\Delta T)$ is derived from the GEOS Data Assimilation System (DAO, 1996). Surface skin temperatures $\left(T_{\mathrm{s}}\right)$ are estimated from MODIS clear-sky $11 \mu \mathrm{m}$ radiance (Minnis et al., 2004). The CERES SSF algorithm uses $\Delta T, T_{\mathrm{s}}$ and TPW to define sub-scene types of clear-sky observations. Thus, the OLR can be inverted using appropriated broadband ADM and measured broadband radiances (Loeb et al., 2005; Kato and Loeb, 2005). The uncertainty of inverted CERES OLR is about $1 \%$ (Loeb et al., 2007).

The European Centre for Medium-range Weather Forecasting (ECMWF) ERA-Interim reanalysis (Dee et al., 2011) is used in this study as well. It has a spatial resolution of $1.5^{\circ}$ latitude by $1.5^{\circ}$ longitude and 37 vertical levels up to $1 \mathrm{hPa}$. Similar to Huang et al. (2008) and Chen et al. (2013), the forward radiative transfer model used here is the MODerate resolution atmospheric TRANsmission code (MODTRAN, version 5; Anderson et al., 2007). MODTRAN 5 is used to compute synthetic AIRS radiances and outgoing spectral fluxes at the top of atmosphere (TOA). MODTRAN 5 offers a spectral resolution as fine as $0.1 \mathrm{~cm}^{-1}$ (higher than AIRS spectral resolution). Compared with AIRS observations, MODTRAN 5 replicates AIRS brightness temperatures over $650-1600 \mathrm{~cm}^{-1}$ with a mean difference of $\sim 0.2 \mathrm{~K}$ (the AIRS noise equivalent delta temperature (NEDT) being $0.51 \mathrm{~K}$ over this band) (Anderson et al., 2007). AIRS radiances are generated by convoluting MODTRAN 5 output and tabulated spectral response functions of AIRS channels (Strow et al., 2006). The TOA spectral fluxes are computed using a three-point Gaussian quadrature (Clough and Iacono, 1995).

\section{Algorithm for estimating clear-sky LW spectral flux: the case of nadir view}

The algorithm for estimating clear-sky LW spectral flux from nadir-view AIRS spectral radiances consists of three steps. The first step is to use radiance alone to decide whether an AIRS spectrum can be considered as a clear-sky spectrum or not (usually referred as clear-sky detection). The second step is to classify the sub-scene type of a clear-sky spectrum using radiance information alone. The third step is to invert the AIRS radiances to spectral flux over the entire LW spectrum.

\subsection{Clear-sky detection}

\subsubsection{Algorithm design}

Detecting clear-sky scenes from IR radiance alone is usually done by applying a sequence of tests (Amato et al., 2014, and references therein). We use three tests in sequence for this purpose. Test 1 is a spatially inhomogeneous test com- monly referred as the "golden-arches" test, proposed first by Coakley and Bretherton (1983). For a given AIRS footprint and four adjacent AIRS footprints, if the standard deviation of brightness temperatures at a window channel $963.8 \mathrm{~cm}^{-1}$ (hereafter denoted as $\mathrm{BT}_{963.8}$ ) is smaller than a predetermined threshold value $\mathrm{C} 1$, the footprint passes test 1 . For the footprint that passes the golden-arches test, test 2 is a bi-spectral test, namely the brightness temperature difference between two narrow bands, one being an $8 \mu \mathrm{m}$ band $\left(\mathrm{BT}_{8}, 1121.0-1223.6 \mathrm{~cm}^{-1}\right)$ and the other being an $11 \mu \mathrm{m}$ band $\left(\mathrm{BT}_{11}, 888.7-994.1 \mathrm{~cm}^{-1}\right)$. Test 2 utilizes the spectrally dependent feature to distinguish cloudy spectrum and clearsky spectrum, because the $11 \mu \mathrm{m}$ band is sensitive to water clouds and ice clouds, while the $8 \mu \mathrm{m}$ band has weak water vapor absorption lines, and the $\mathrm{BT}_{8}-\mathrm{BT}_{11}$ difference has been widely used for this purpose (e.g., Ackerman and Strabala, 1994). If the $\mathrm{BT}_{8}-\mathrm{BT}_{11}$ difference of an AIRS spectrum is less than a predetermined value $\mathrm{C} 2$, the spectrum passes test 2 . Test 3 is a threshold test to compare the $\mathrm{BT}_{963.8}$ with the surface temperature at the ground footprint interpolated from 6-hourly ERA-Interim reanalysis, termed $T_{\mathrm{SERA}_{\mathrm{ER}}-}$ $\mathrm{BT}_{963.8}$. $\mathrm{BT}_{963.8}$ is used as a surrogate of surface temperature in Chen and Huang (2014) because this channel has little atmospheric absorption in the case of clear sky. If $T_{\mathrm{SERA}_{\mathrm{EA}}}$ $\mathrm{BT}_{963.8}$ of an AIRS spectrum is smaller than a predetermined value $\mathrm{C} 3$, the spectrum passes test 3 . Only when a spectrum passes all three tests do we deem it to be a clear-sky spectrum. Note that, though ERA-Interim reanalysis is used in this study, in future operational applications the reanalysis surface temperature can be replaced by the surface temperature from operational analysis.

We used 4 months of collocated AIRS and CERES nadirview observations in 2006 to empirically determine the threshold values used in the three tests (i.e., C1, C2 and C3). In other words, we use the clear-sky footprint identified by CERES as the "ground truth" and decide the threshold values based on collocated AIRS observations accordingly. The 4 months used for this purpose are January, April, July and October of 2006. A total of $\sim 1.56$ million collocated observations are available for this training purpose. We first categorize the observations into four groups: daytime ocean, nighttime ocean, daytime land and nighttime land. Then for each group, the threshold value is defined as the value suitable for describing $95 \%$ of qualified observations. An example of how to decide $\mathrm{C} 1$ is given in Fig. 1. Each panel plots the histogram of the standard deviation based on the $\mathrm{BT}_{963.8}$ of the clear-sky AIRS footprint and four adjacent AIRS footprints. Only $5 \%$ of clear-sky observations in each panel have a standard deviation larger than the value denoted by the dashed line, which is then assigned as the value of $\mathrm{C} 1$. The value of $\mathrm{C} 2$ is decided in a similar manner. Water vapor continuum absorption is important for the AIRS channel at $963.8 \mathrm{~cm}^{-1}$. Such absorption is dominated by humidity in the planetary boundary layer, which is highly correlated with surface temperature. Therefore, we divide observations fur- 
Table 1. Threshold values used in the clear-sky tests. Details of threshold definitions and the ways to determine them can be found in Sect. 3.1.

\begin{tabular}{|c|c|c|c|c|}
\hline Thresholds & Daytime ocean & Nighttime ocean & Daytime land & Nighttime land \\
\hline $\mathrm{C} 1(\mathrm{~K})$ & 0.62 & 0.61 & 2.17 & 1.650 \\
\hline $\mathrm{C} 2(\mathrm{~K})$ & -1.39 & -1.38 & -2.04 & -0.510 \\
\hline \multirow[t]{6}{*}{$\mathrm{C} 3(\mathrm{~K})$} & $2.47\left(T_{\mathrm{S}_{\mathrm{ERA}}}<280 \mathrm{~K}\right)$ & $2.29\left(T_{\mathrm{S}_{\mathrm{ERA}}}<280 \mathrm{~K}\right)$ & $1.24\left(T_{\mathrm{S}_{\mathrm{ERA}}}<290 \mathrm{~K}\right)$ & $2.28\left(T_{\mathrm{S}_{\mathrm{ERA}}}<260 \mathrm{~K}\right)$ \\
\hline & $3.12(280-285 \mathrm{~K})$ & $3.12(280-285 \mathrm{~K})$ & $1.49(290-295 \mathrm{~K})$ & $5.41(260-270 \mathrm{~K})$ \\
\hline & $3.61(285-290 \mathrm{~K})$ & $3.11(285-290 \mathrm{~K})$ & $3.28(295-300 \mathrm{~K})$ & $5.61(270-275 \mathrm{~K})$ \\
\hline & $3.61(290-295 \mathrm{~K})$ & $3.54(290-295 \mathrm{~K})$ & $3.99(300-305 \mathrm{~K})$ & $6.72(275-280 \mathrm{~K})$ \\
\hline & $3.95(295-300 \mathrm{~K})$ & $4.13(295-300 \mathrm{~K})$ & $5.31(305-310 \mathrm{~K})$ & $7.36(280-285 \mathrm{~K})$ \\
\hline & $5.49(>300 \mathrm{~K})$ & $5.82(>300 \mathrm{~K})$ & $5.76(>310 \mathrm{~K})$ & $8.25(>285 \mathrm{~K})$ \\
\hline
\end{tabular}

Table 2. The performance of clear-sky detection algorithm. FN (false negative) is the percentage of CERES clear-sky observations misclassified as cloudy sky by the algorithm. FP (false positive) is the percentage of CERES cloudy-sky observations misclassified as clear sky by the algorithm. Merit function is the overall success rate compared to the CERES algorithm in terms of distinguishing clear- vs. cloudy-sky observations. Steps 1-3 are defined in detail in Sect. 3.1.

\begin{tabular}{lrrr|rrr|rrr}
\hline & \multicolumn{3}{c|}{ Ocean } & \multicolumn{2}{c|}{ Land } & \multicolumn{2}{c}{ Near global $\left(81^{\circ} \mathrm{S}-81^{\circ} \mathrm{N}\right)$} \\
\cline { 2 - 9 } & FN (\%) & FP (\%) & $\begin{array}{r}\text { Merit } \\
\text { function (\%) }\end{array}$ & FN (\%) & FP (\%) & $\begin{array}{r}\text { Merit } \\
\text { function (\%) }\end{array}$ & FN (\%) & $\begin{array}{r}\text { FP (\%) } \\
\text { function (\%) }\end{array}$ \\
\hline Step 1 & 4.8 & 19.7 & 81.3 & 6.2 & 33.1 & 71.1 & 5.4 & 22.4 & 79.1 \\
Steps 1 +2 & 9.7 & 14.1 & 86.2 & 10.0 & 19.2 & 82.2 & 9.8 & 15.2 & 85.3 \\
Steps 1+2+3 & 13.9 & 10.0 & 89.8 & 14.0 & 15.4 & 84.8 & 13.9 & 11.1 & 88.7 \\
\hline
\end{tabular}

ther into different subgroups based on the value of $T_{\mathrm{SERA}}$, and the value of C3 is determined for each subgroup accordingly. Table 1 summarizes the threshold values for $\mathrm{C} 1, \mathrm{C} 2$ and $\mathrm{C} 3$ derived in this manner.

\subsubsection{Performance of the clear-sky test algorithm}

We assess the performance of the clear-sky test algorithm using collocated CERES and AIRS nadir-view observations in the entire year of 2004 (4.48 million observations in total). The performance is summarized in Table 2. The falsenegative $(\mathrm{FN})$ rate refers to the percentage of collocated CERES clear-sky observations that have been classified as cloudy-sky observations by our algorithm. The false-positive (FP) rate refers to the percentage of collocated CERES cloudy-sky observations that have been classified as clearsky observations by our algorithm. The merit function refers to the percentage of successful classifications by our algorithm for all cloudy- and clear-sky footprints. The definition of FN, FP and merit function follows Amato et al. (2014). It can be seen that, although using three tests together increases the rate of false negative, such an approach is also effective in reducing the false-positive rate. Given that the number of cloudy-sky observations is $\sim 9-10$ times more than that of clear-sky observations, using three tests together can achieve a better accuracy than using one of the tests alone. As far as the FN and FP rates are concerned, this algorithm is comparable to other clear-sky detection algorithms that are based
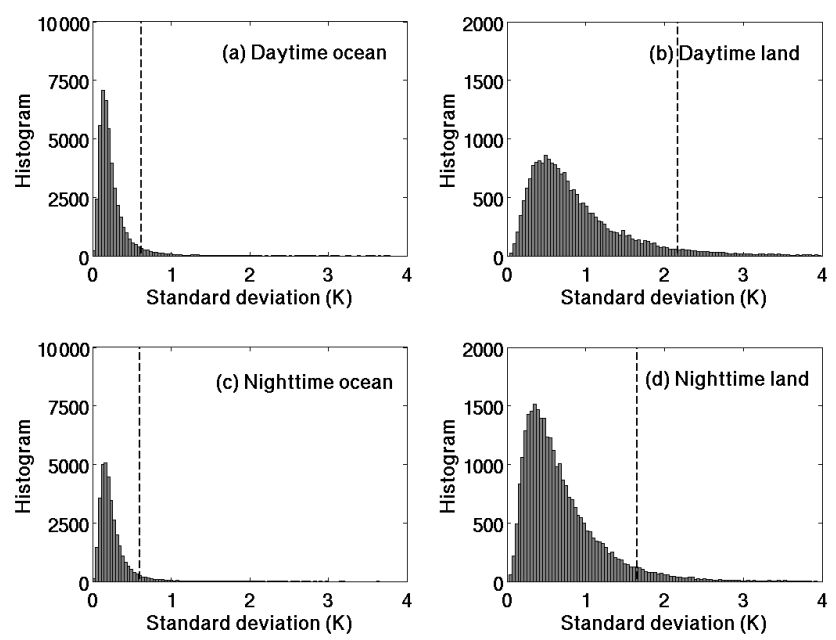

Figure 1. Histogram of the standard deviations of $963.8 \mathrm{~cm}^{-1}$ brightness temperatures for an AIRS clear-sky footprint and four adjacent AIRS footprints. The clear-sky information from collocated CERES observation is used. The histograms for daytime ocean, daytime land, nighttime ocean and nighttime land are plotted separately. One hundred bins are used in each panel. The black dashed line denotes the $95 \%$ percentile and corresponds to the value of $\mathrm{C} 1$ shown in Table 1.

on IR spectral radiances alone (e.g., Table 4 in Amato et al., 2014). The number of clear-sky AIRS footprints detected by this algorithm is nearly two times the number of clear- 
Table 3. Accuracy of the sub-scene type classification algorithm described in Sect. 3.2. The statistics are based on collocated nadir-view AIRS and CERES observations in 2004. "Occ." and "Acc." in the Table denote occurrence and accuracy, respectively. The sub-scene type is coded as a three-digit number. The first digit refers to TPW, the second one refers to $\Delta T$ and the last refers to $T_{\mathrm{S}}$, as defined in the table. The definition of sub-scene types here is identical to the LW discrete intervals in Loeb et al. (2005).

\begin{tabular}{|c|c|c|c|c|c|c|c|c|c|c|c|}
\hline $\begin{array}{l}\text { Sub-scene } \\
\text { type }\end{array}$ & $\begin{array}{l}\text { TPW } \\
(\mathrm{cm})\end{array}$ & $\begin{array}{r}\text { Occ. } \\
(\%)\end{array}$ & $\begin{array}{l}\text { Acc. } \\
(\%)\end{array}$ & $\begin{array}{l}\text { Sub-scene } \\
\text { type }\end{array}$ & $\begin{array}{l}\Delta T \\
(\mathrm{~K})\end{array}$ & $\begin{array}{r}\text { Occ. } \\
(\%)\end{array}$ & $\begin{array}{l}\text { Acc. } \\
(\%)\end{array}$ & $\begin{array}{r}\text { Sub-scene } \\
\text { type }\end{array}$ & $\begin{array}{r}T_{\mathrm{S}} \\
(\mathrm{K})\end{array}$ & $\begin{array}{r}\text { Occ. } \\
(\%)\end{array}$ & $\begin{array}{l}\text { Acc. } \\
(\%)\end{array}$ \\
\hline $1--$ & $0-1$ & 16.3 & 63.1 & $-1-$ & $<15$ & 32.9 & 70.5 & --1 & $<270$ & 1.24 & 99.8 \\
\hline $2--$ & $1-3$ & 55.0 & 86.8 & $-2-$ & $15-30$ & 65.8 & 85.1 & --2 & $270-290$ & 24.7 & 98.2 \\
\hline $3--$ & $3-5$ & 25.7 & 82.0 & $-3-$ & $30-45$ & 1.29 & 48.4 & --3 & $290-310$ & 73.1 & 93.2 \\
\hline \multirow[t]{2}{*}{$4--$} & $>5$ & 3.0 & 53.8 & $-4-$ & $>45$ & 0.002 & 16.7 & --4 & $310-330$ & 0.98 & 22.1 \\
\hline & & & & & & & & --5 & $>330$ & 0.0 & - \\
\hline Overall & & 100 & 80.7 & & & 100 & 79.8 & & & 100 & 93.8 \\
\hline
\end{tabular}

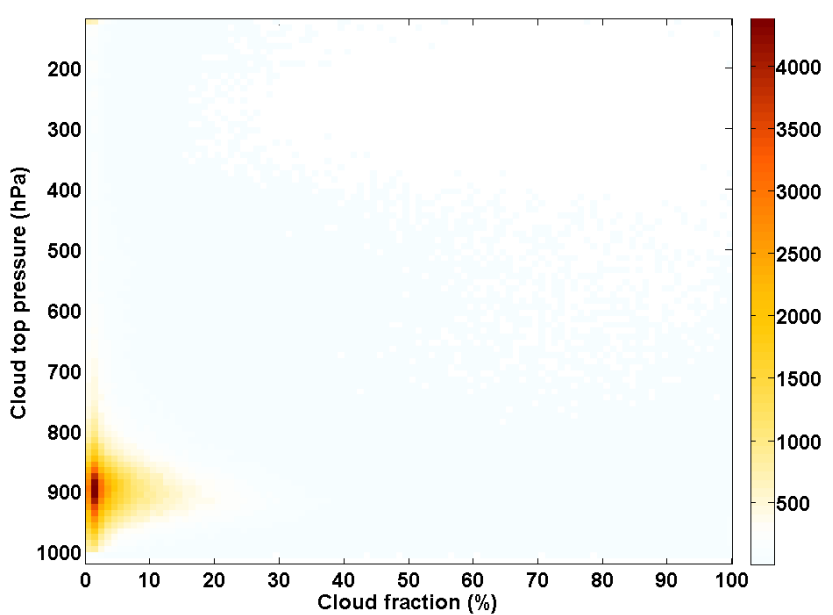

Figure 2. Number of AIRS footprints that are misclassified as clearsky footprints as a function of cloud fraction and cloud top pressure. The cloud information is from the collocated CERES SSF data product.

sky footprints from the collocated CERES SSF data set. The overwhelming majority of misclassified footprints are those with cloud top pressure $\geq 900 \mathrm{hPa}$ and cloud fraction $\leq 10 \%$, as shown in Fig. 2. In other words, for footprints with low cloud and very small cloud fraction, the IR-alone detection algorithm has difficulty distinguishing it from the clear-sky footprint, which is consistent with previous IR-based clearsky detection results. As shown later in Fig. 6 and the related discussion, the OLR estimated for these misclassified footprints is indeed similar to the collocated CERES OLR, largely because of the very limited cloud fraction in the footprints.

\subsection{Sub-scene type classification}

The second step in the overall algorithm is to classify the sub-scene types of clear-sky observations identified by the algorithm described in Sect. 3.1. The sub-scene types adopted here are largely similar to the discrete intervals defined by Table 3 in Loeb et al. (2005), which depend on the TPW, surface temperature $\left(T_{\mathrm{S}}\right)$ and lapse rate $(\Delta T)$ defined as the temperature difference between the surface and $300 \mathrm{hPa}$ above it. Similar to Chen and Huang (2014), here BT 963.8 is used as a surrogate of surface temperature. $\Delta T$ is inferred from brightness temperature differences of two AIRS channels: 963.8 and $748.6 \mathrm{~cm}^{-1}$ (hereafter denoted as $\Delta \mathrm{BT}_{963.8-748.6}$ ). A quick estimate of TPW is obtained by a lookup table approach proposed by Chen and Huang (2014), which makes use of double difference of two pairs of AIRS channels as well as $\mathrm{BT}_{963.8}$ and $\Delta \mathrm{BT}_{963.8-748.6}$ to construct the lookup table. Table 3 lists the accuracy of this algorithm based on the collocated AIRS and CERES observations in 2004 and the comparison with the auxiliary information of TPW, $T_{\mathrm{S}}$ and $\Delta T$ in the CERES SSF data set. It can be seen that, though this estimate method is solely based on AIRS radiances, the accuracy is $80 \%$ or even higher.

\subsection{Estimate of fluxes from radiance measurements}

The last component in our algorithm is to invert spectral fluxes from the AIRS radiances. Huang et al. (2008) adopted the same sub-scene type classification as in Loeb et al. (2005) for inverting AIRS radiance to spectral flux. Therefore, the algorithm in Huang et al. (2008) can be used here without further modification. Specifically, the spectral radiance $\left(I_{\mathrm{AIRS}}(\theta)\right.$ at each viewing zenith angle $\left.\theta\right)$ is first converted to spectral flux ( $\left.F_{\text {AIRS }}\right)$ over each AIRS channel using a pre-calculated anisotropic factor $R_{\mathrm{AIRS}}(\theta)$ based on the spectral ADM for each sub-scene type; i.e., $F_{\text {AIRS }}=\pi \cdot I_{\text {AIRS }}(\theta) / R_{\text {AIRS }}(\theta)$ (Huang et al., 2008). Then a principle component-based multivariate prediction scheme is used to estimate spectral fluxes over the spectral portion $\left(<649.6,1136.6-1217.0\right.$ and $\left.1613.9-2000 \mathrm{~cm}^{-1}\right)$ not covered by the AIRS instrument. Details can be found in Huang et al. (2008). The performance of this radiance-to-flux algorithm and its characteristics has been documented in detail in Huang et al. (2008) and Chen et al. (2013). 


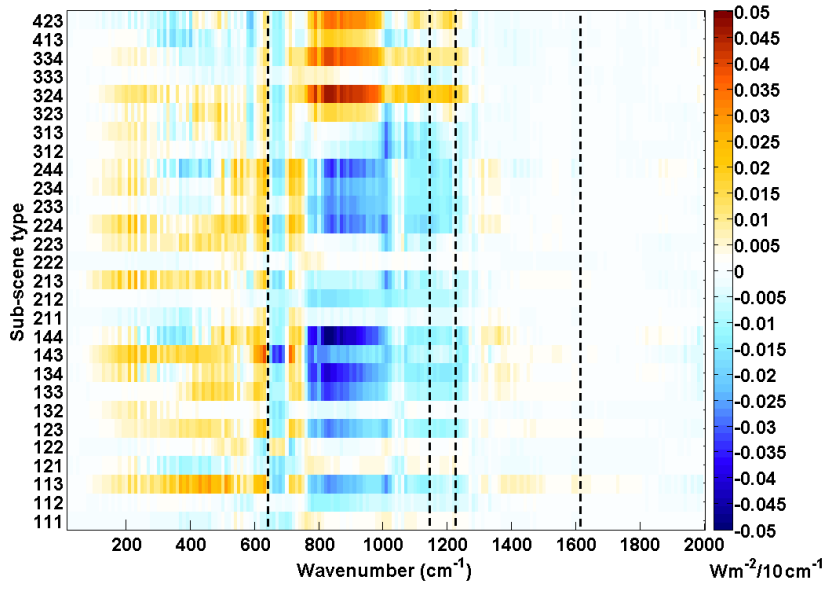

Figure 3. The mean differences between the predicted spectral fluxes based on synthetic AIRS spectra and the directly computed fluxes for different sub-scene types. The naming convention of subscene types is defined in Table 3. The spectral flux is for every $10 \mathrm{~cm}^{-1}$ interval from 10 to $2000 \mathrm{~cm}^{-1}$. Spectral bands between two pairs of dashed lines are covered by the AIRS instrument.

\section{Validation of the overall algorithm}

This section focuses on validation of the overall algorithm in terms of its performance in estimating the spectral flux over the entire longwave spectrum. The following parts 13 examine the performance of the scene type classification algorithm, and part 4 examines the overall performance of the clear-sky detection and the scene type classification algorithms.

1. We feed 6-hourly ERA-Interim reanalysis data to the forward model to simulate clear-sky AIRS radiances and apply our algorithm to estimate the spectral flux (hereafter $F_{\text {AIRS-only). We then compare this spectral }}$ flux with clear-sky spectral fluxes directly computed using the ECMWF ERA-Interim reanalysis with the same forward model (hereafter $F_{\mathrm{ERA}}$ ). This is an idealized test because the forward modeling is assumed to be a surrogate of reality. Specifically, 6-hourly ERA-Interim reanalysis data from January, April, July and October 2004 are subsampled and interpolated onto the trajectory of AIRS nadir-view observations. Then MODTRAN 5 is used to generate synthetic AIRS radiances and synthetic spectral flux $F_{\text {ERA }}$. Then $F_{\text {AIRS-only is de- }}$ rived from synthetic AIRS radiances based on the scene types determined from synthetic AIRS radiances alone, instead of directly determined from ERA profiles as in our previous works of Huang et al. (2008) and Chen et al. (2013). In total 290761 profiles are used, and the number of profiles for each sub-scene type varies from 50 to 64992 . The averaged difference of the spectral flux for each scene type, denoted as $F_{\text {AIRS-only }}-F_{\text {ERA }}$, at $10 \mathrm{~cm}^{-1}$ spectral interval is shown in Fig. 3. For the window bands, the differences $\left(F_{\text {AIRS-only }}-F_{\text {ERA }}\right)$ are generally within $\pm 0.03 \mathrm{Wm}^{-2}$ per $10 \mathrm{~cm}^{-1}$. Exceptions are seen for those sub-scene types with very dry atmosphere above a hot surface. These circumstances make it difficult for our radiance-based algorithm to faithfully estimate the TPW. As shown in Table 3, the frequency of occurrences for such scene types is small; e.g., hot surface with temperature above $310 \mathrm{~K}$ is no more than $1 \%$. Outside the window bands, the $F_{\text {AIRS-only }}-F_{\text {ERA }}$ differences are usually within $\pm 0.02 \mathrm{Wm}^{-2}$ per $10 \mathrm{~cm}^{-1}$.

2. For collocated AIRS and CERES clear-sky observations in 2004, we use the algorithm to derive the spectral flux and OLR (the summation of spectral flux) from

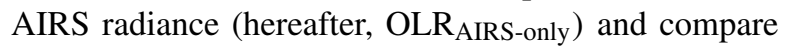
it with the collocated CERES clear-sky OLR (hereafter OLR $\left._{\text {CERES }}\right)$. Upper panels in Fig. 4 show the annual-mean daytime and nighttime difference between OLR AIRS-only $_{\text {and OLR }}$ CERES. The differences are averaged onto $2^{\circ}$ latitude by $2.5^{\circ}$ longitude grids from $80^{\circ} \mathrm{S}$ to $80^{\circ} \mathrm{N}$. Lower panels in Fig. 4 show the histograms

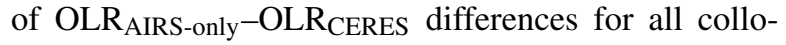
cated AIRS and CERES clear-sky footprints. Figure 4a and $\mathrm{b}$ show that the difference tends to be negative over land areas $\left(\sim 1-2 \mathrm{Wm}^{-2}\right)$ and positive over extratropical oceans $\left(\sim 1-3 \mathrm{Wm}^{-2}\right)$. The rms (root-mean-square) differences for Fig. $4 \mathrm{a}$ and $\mathrm{b}$ are 1.79 and $1.11 \mathrm{Wm}^{-2}$, respectively. Such a pattern and magnitude of the differences in Fig. 4a and b are comparable to the results using the scene type information directly from the CERES SSF data set, as shown in Fig. 5a and b in Chen et al. (2013). In terms of the statistics of the OLR AIRS-only-

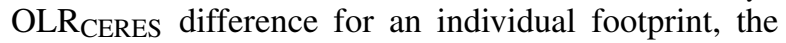
daytime mean difference is $0.91 \mathrm{Wm}^{-2}$ with a standard deviation of $2.34 \mathrm{Wm}^{-2}$ (Fig. 4c), and the nighttime mean difference is $0.14 \mathrm{Wm}^{-2}$ with a standard deviation of $1.85 \mathrm{Wm}^{-2}$ (Fig. 4d). These statistics are comparable to those in Huang et al. (2008) and Chen et al. (2013).

3. We examine the statistics of OLR $\mathrm{OIRS}_{\text {AInly }}-\mathrm{OLR}_{\mathrm{CERES}}$ differences for each available clear-sky sub-scene type in the data used in part 2. The results are summarized in Fig. 5. The averaged daytime OLR $_{\text {AIRS-only }}-$ OLR CERES $_{\text {S }}$ differences for all sub-scene types are between -1.6 and $3.3 \mathrm{Wm}^{-2}$ with a standard deviation no larger than $3.8 \mathrm{Wm}^{-2}$. For the nighttime, the mean difference for all sub-scene types varies from -0.7 to $2.2 \mathrm{Wm}^{-2}$, and the standard deviation is less than $2.5 \mathrm{Wm}^{-2}$. Given that the radiometric uncertainty of CERES OLR is about $1 \%$ and the typical OLR value varies between 200 and $300 \mathrm{Wm}^{-2}$, the mean differences (black line in Fig. 5) are within or at least comparable to the radiometric uncertainty of CERES OLR (red line in Fig. 5).

4. In addition to using collocated clear-sky observations to evaluate the algorithm, we also apply the algorithm 

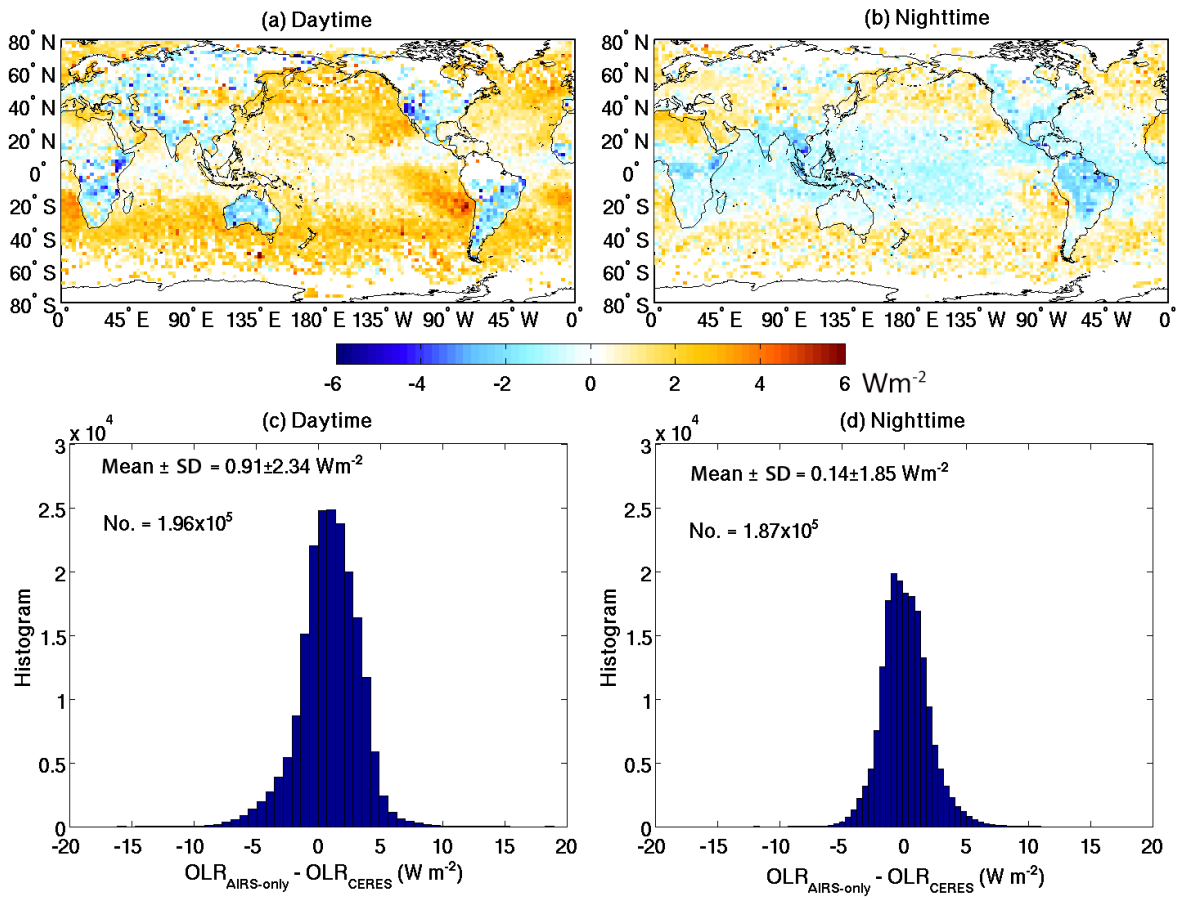

Figure 4. (a) Near-global distribution of annual-mean differences between daytime OLR derived from clear-sky AIRS nadir-view radiances using the algorithm in this study and the collocated CERES clear-sky daytime OLR (OLR AIRS-only $_{\text {-OLR }}$ CERES $)$. The data in 2004 are used and averaged onto $2.5^{\circ}$ longitude by $2^{\circ}$ latitude grids. (b) Same as (a) but for annual-mean nighttime OLR differences. (c) The histograms of daytime OLR AIRS-only $-\mathrm{OLR}_{\text {CERES }}$ differences among all collocated AIRS and CERES nadir-view footprints. (d) Same as (c) but for

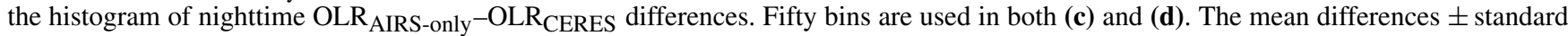
deviations and number of observations are also labeled on the plot.

to all collocated AIRS and CERES nadir-view observations in the entire year of 2004 and obtain OLR for all AIRS measurements that our algorithm determines to be clear-sky observations. The mean difference is $1.52 \mathrm{Wm}^{-2}$ and standard deviation is $2.46 \mathrm{Wm}^{-2}$. The figure is not shown here. We then compare the OLR of those "false-positive" observations, i.e., footprints identified as clear-sky scenes by our algorithm but as cloudy-sky scenes by the CERES algorithm. Figure 6 shows the histograms of OLR differences (OLR AIRS-only $_{\text {-OLR }}$ CERES $)$ of such cases of a false positive. The mean difference is 2.93 and $1.60 \mathrm{Wm}^{-2}$ for the daytime and nighttime, respectively. The standard deviation is $2.3 \mathrm{Wm}^{-2}$ for both cases. The mean OLR for the cases shown in Fig. 6a and b is 288.7 and $279.0 \mathrm{Wm}^{-2}$, respectively, which means the relative dif-

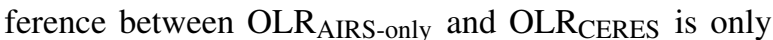
1.0 and $0.6 \%$. This suggests that, even though the algorithm misclassifies such cloudy-sky observations as clear-sky ones, the estimated OLR difference between OLR $_{\text {AIRS-only }}$ and OLR $R_{\text {CERES }}$ is only $1 \%$ or less.

\section{Applicability to other viewing zenith angles}

The algorithm described above is for nadir-view AIRS radiances. It can be extended to other viewing zenith angles by taking the dependency of upwelling radiances on viewing zenith angles into account. Specifically, for the first two steps depicted in Sect. 3, the threshold values and lookup tables need to be adjusted in accordance with the viewing zenith angles. The algorithm in the third component has already taken viewing zenith angle into account (Huang et al., 2008), and thus no additional effort is needed. Since the objective of this study is to demonstrate the feasibility of the algorithm, we summarize the performance of the algorithm for other VZAs instead of describing all details as done for the case of nadir-view observations. Figure 7a shows the success rate for the algorithm to accurately classify cloudy and clear-sky footprints as a function of the VZA, which still uses the collocated CERES scene type information as the ground truth. The algorithm performs consistently across all VZAs; when the VZA increases from 0 to $45^{\circ}$, the success rate varies within $2 \%$. Figure $7 \mathrm{~b}$ shows the differences between

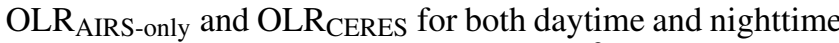
results. Both differences, $1.93-2.15 \mathrm{Wm}^{-2}$ for daytime and $1.07-1.67 \mathrm{Wm}^{-2}$ for nighttime, change little with respect to the VZA. 
(a) Daytime

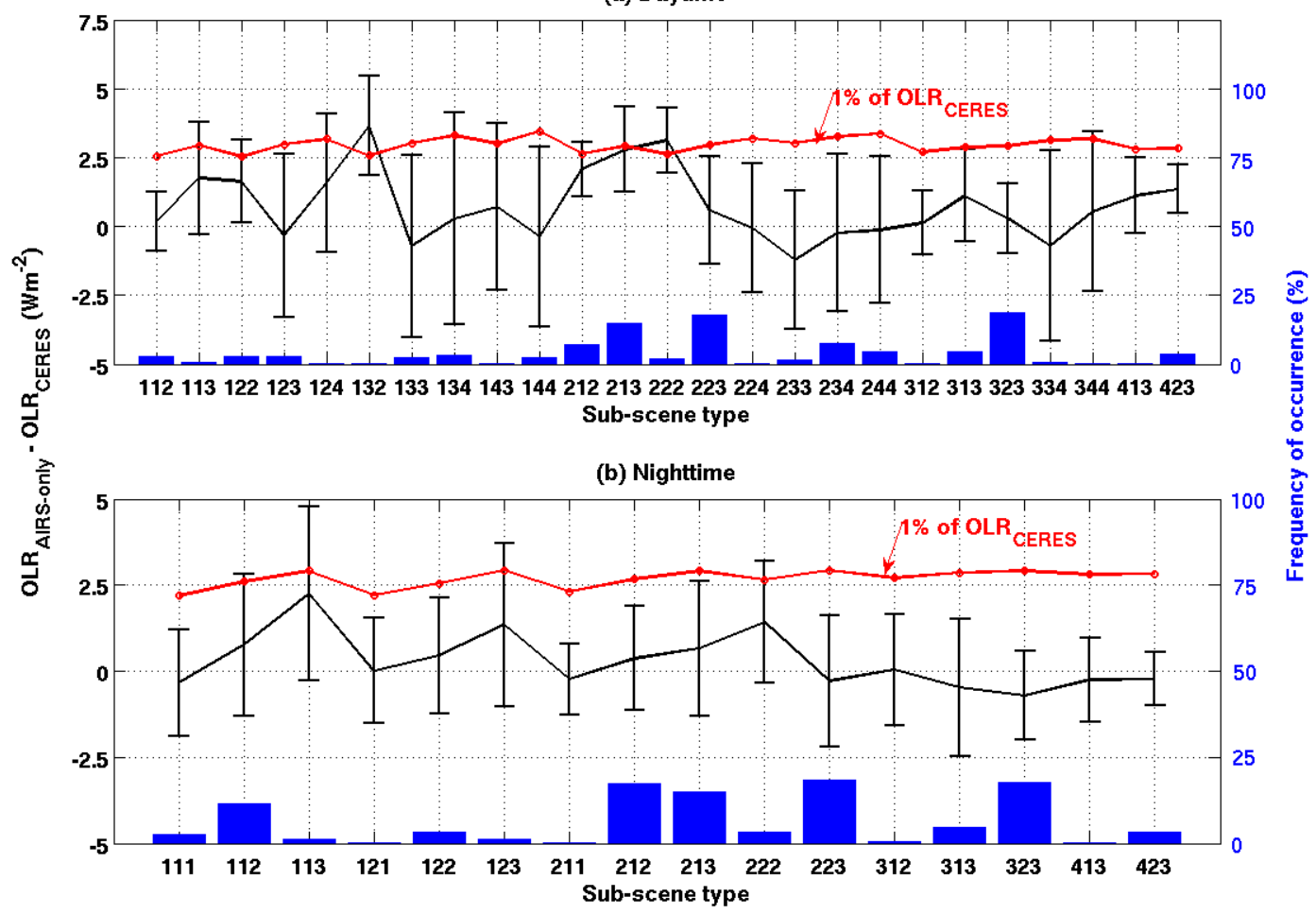

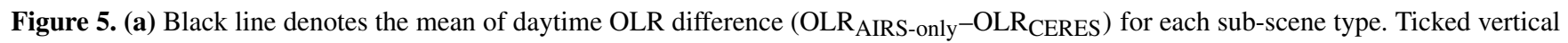

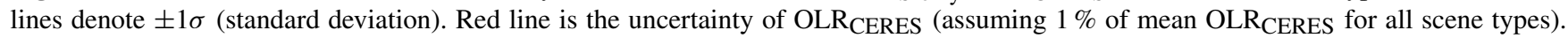
Blue bars indicate the frequency of occurrence of each sub-scene type in percentage. (b) Same as (a) but for nighttime observations. The numbers of daytime and nighttime observations are $1.86 \times 10^{5}$ and $1.87 \times 10^{5}$, respectively.

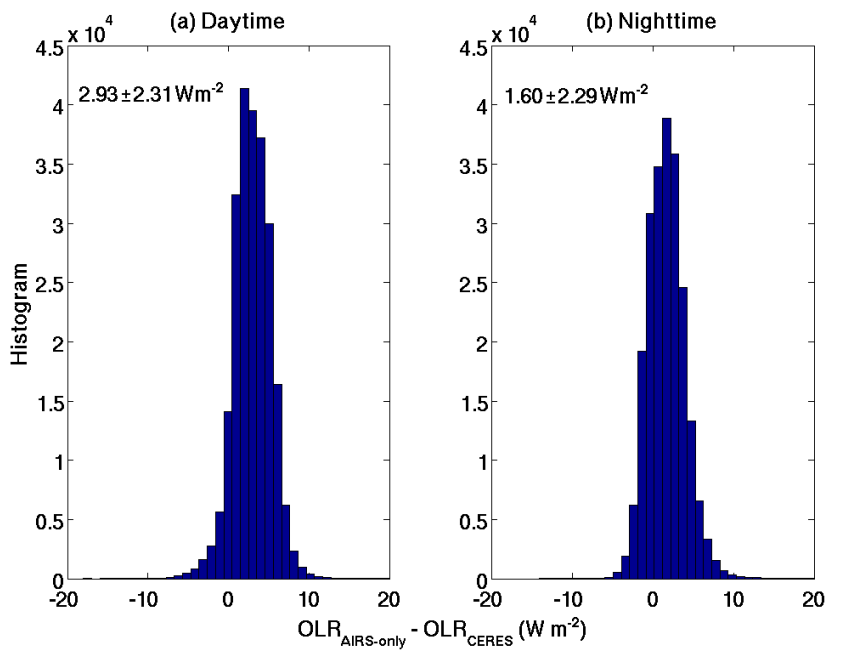

Figure 6. (a) and (b) are similar to Fig. 4c and d but for the AIRS footprints classified as clear sky by the algorithm in this study, while their collocated CERES footprints are identified as cloudy sky. Mean \pm standard deviation of the difference (OLR AIRS-only $^{-}$

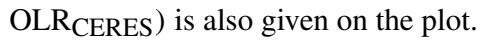
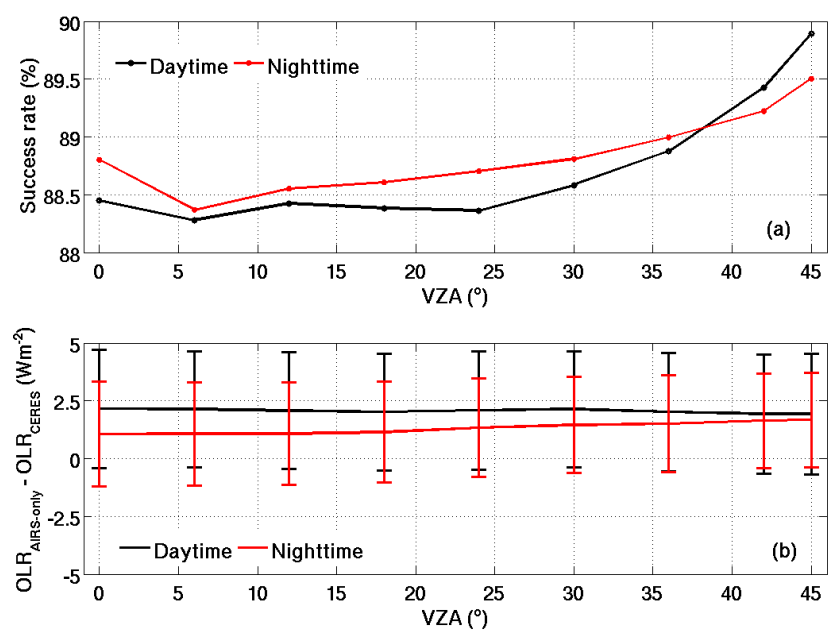

Figure 7. (a) Success rate of the algorithm in distinguishing clearsky and cloudy-sky footprints as a function of viewing zenith angle (VZA). (b) The difference of OLR AIRS-only-OLR CERES $_{\text {as a }}$ function of VZA. Ticked vertical lines denote the $\pm 1 \sigma$ (standard deviation) 
The performance with respect to different VZAs here is consistent with previous results in Huang et al. (2008) and Chen et al. (2013), two studies that rely on the sub-scene type information from the CERES SSF data set. The algorithm in this study behaves robustly across the range of VZAs for AIRS measurements. The other hyperspectral sounders make observations over a similar range of VZAs. Therefore, the robust performances here further assure the potential of extending the algorithm to other hyperspectral sounding observations.

\section{Conclusions and discussion}

Using AIRS observation as an example, this study develops an algorithm based on spectral radiances to estimate LW clear-sky spectral flux. The algorithm first detects clearsky spectrum by a three-step threshold test, i.e., the goldenarches test for the spatial homogeneity, a bi-spectral test for spectral features of clear-sky absorption and emission and a single-channel thermal threshold test for an extra check against surface temperature. Atmospheric and surface parameters (total precipitable water, lapse rate and surface temperature) needed for categorizing sub-scene types are directly estimated using AIRS radiances at six channels and the pre-constructed lookup tables. The accuracy of clear-sky detection and sub-scene type classification as well as their effect on clear-sky spectral flux derivation have been assessed. When using CERES scene type information as the ground truth, the algorithm can achieve an accuracy rate of $88.7 \%$ for classifying nadir-view clear-sky and cloudy footprints. Differences between OLR derived using the algorithm and the collocated CERES OLR show no strong dependence on the sub-scene types. The statistics of OLR AIRS-only-

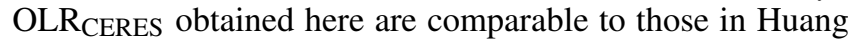
et al. (2008) and Chen et al. (2013), two studies that directly used the scene-type and clear-sky information from the CERES data set. The algorithm performs consistently over different viewing zenith angles.

The purpose of this study is to explore the additional value of hyperspectral sounding measurements, i.e., by deriving spectral flux directly from such observations as the spectral fluxes that have been shown to have unique merit in climate model evaluations (Huang et al., 2006, 2013, 2014). The broadband flux measured by CERES and its predecessor ERBE has become a benchmark standard in the earth observation community, as has the sophisticated and wellvalidated multiple data-fusion approach used in the CERES data product. It is not the intention of this study to produce merely another set of broadband flux products. Instead, the emphasis here is to derive the spectral flux, which can help us understand the compensating biases in modeled broadband radiation flux.

In general, the performance of the algorithm is more affected by the accuracy of clear-sky detection than the rest of the components. To use LW spectral observations alone to detect clear sky is not easy, partially because it is difficult to distinguish optically thin clouds or small fraction of clouds within the field of view. In operational use, the accuracy of clear-sky detection could be improved if other simultaneous measurements, especially those made at higher spatial resolutions, were available. A good example is the use of MODIS imageries in the CERES SSF algorithm. Another example is the use of microwave sounding observations to help the surface parameter retrievals, which in turn helps the retrievals of atmospheric parameters including the cloud vs. clear-sky detection (Kahn et al., 2014).

While the algorithm presented in this study is only for clear-sky spectra, it is conceivable that this algorithm can be evolved for estimating spectral fluxes from cloudy-sky hyperspectral observations as well. In the case of cloudy-sky spectra, the cloud parameters, especially cloud fraction and cloud top height, will need to be considered in the definition of sub-scene types. The rich information contained in hyperspectral radiances is likely sufficient to define sub-scene types needed for the algorithm.

\section{Data availability}

The AIRS Level 1B data are downloadable from NASA GES DISC (http://airsl1.gesdisc.eosdis.nasa. gov/data/Aqua_AIRS_Level1/AIRIBRAD.005/, GES DISC, 2016), and the Aqua CERES data were obtained from NASA Atmospheric Science Data Center (https: //eosweb.larc.nasa.gov/HORDERBIN/HTML_Start.cgi, ASDC, 2016). The ECMWF ERA-Interim data are from http://apps.ecmwf.int/datasets/data/interim-full-daily/ levtype=p1/ (ECMWF, 2016).

Acknowledgements. We wish to thank two anonymous reviewers for their thorough and thoughtful comments, which helped us greatly improve the clarity of the presentation. This research is supported by NASA under grants NNX14AJ50G and NNX15AC25G awarded to the University of Michigan.

Edited by: J. Nothol

Reviewed by: two anonymous referees

\section{References}

Ackerman, S. A. and Strabala, K. I.: Satellite remote sensing of $\mathrm{H}_{2} \mathrm{SO}_{4}$ aerosol using the 8- to $12-\mu \mathrm{m}$ window region: Application to Mount Pinatubo, J. Geophys. Res.-Atmos., 99, 1863918649, 1994.

Amato, U., Lavanant, L., Liuzzi, G., Masiello, G., Serio, C., Stuhlmann, R., and Tjemkes, S. A.: Cloud mask via cumulative discriminant analysis applied to satellite infrared observations: scientific basis and initial evaluation, Atmos. Meas. Tech., 7, 3355-3372, doi:10.5194/amt-7-3355-2014, 2014. 
Anderson, G. P., Berk, A., Chetwynd, J. H., Harder, J., Fontenla, J. M., Shettle, E. P., Saunders, R., Snell, H. E., Pilewskie, P., Kindel, B. C., Gardner, J. A., Hoke, M . L., Felde, G. W., Lockwood, R. B., and Acharya, P. K.: Using the MODTRAN5 radiative transfer algorithm with NASA satellite data: AIRS and SORCE. Algorithms and Technologies for Multispectral, Hyperspectral, and Ultraspectral Imagery XIII, Proc. SPIE 6565, 65651O, doi:10.1117/12.721184, 2007.

ASDC: CERES data, NASA Atmospheric Science Data Center, available at: https://eosweb.larc.nasa.gov/HORDERBIN/ HTML_Start.cgi, 2016.

Aumann, H. H., Chahine, M. T., Gautier, C., Goldberg, M. D1, Kalnay, E., McMillin, L. M., Revercomb, H., Rosenkranz, P. W., Smith, W. L., Staelin, D. H., Strow, L. L., and Susskind, J.: AIRS/AMSU/HSB on the aqua mission: Design, science objectives, data products, and processing system, IEEE T. Geosci. Remote Sens., 41, 253-264, 2003.

Barkstrom, B. R.: The Earth Radiation Budget Experiment (ERBE), B. Am. Meteorol. Soc., 65, 1170-1185, 1984.

Chen, X. H. and Huang, X. L.: Usage of differential absorption method in the thermal IR: a case study of quick estimate of clearsky column water vapor, J. Quant. Spectrosc. Ra., 104, 99-106, 2014.

Chen, X. H., Huang, X. L., Loeb, N. G., and Wei, H. L.: Comparisons of clear-sky outgoing far-IR flux inferred from satellite observations and computed from three most recent reanalysis products, J. Climate, 26, 478-494, doi:10.1175/JCLI-D-12-00212.1, 2013.

Clough, S. A. and Iacono, M. J.: Line-by-line calculations of atmospheric fluxes and cooling rates II: Application to carbon dioxide, ozone, methane, nitrous oxide, and the halocarbons, J. Geophys. Res.-Atmos., 100, 16519-16535, 1995.

Coakley, J. A. and Bretherton, F. P.: Cloud cover from highresolution scanner data: Detecting and allowing for partially filled fields of view, J. Geophys. Res., 87, 4917-4932, 1983.

DAO: Algorithm Theoretical Basis Document for Goddard Earth Observing System Data Assimilation System (GOES DAS) With a Focus Version 2. Data Assimilation Off, NASA Goddard Space Flight Cent, Greenbelt, Md, 310 pp., 1996.

Dee, D. P., Uppala, S. M., Simmons, A. J., Berrisford, P., Poli, P., Kobayashi, S., Andrae, U., Balmaseda, M. A., Balsamo, G., Bauer, P., Bechtold, P., Beljaars, A. C. M., van de Berg, L., Bidlot, J., Bormann, N., Delsol, C., Dragani, R., Fuentes, M., Geer, A. J., Haimberger, L., Healy, S. B., Hersbach, H., Hólm, E. V., Isaksen, L., Kållberg, P., Köhler, M., Matricardi, M., McNally, A. P., Monge-Sanz, B. M., Morcrette, J.-J., Park, B.-K., Peubey, C., de Rosnay, P., Tavolato, C., Thépaut, J.-N., and Vitart, F.: The ERA-Interim reanalysis configuration and performance of the data assimilation system, Q. J. Roy. Meteor. Soc., 137, 553597, 2011.

Dessler, A. E., Yang, P., Lee, J., Solbrig, J., Zhang, Z., and Minschwaner, K: An analysis of the dependence of clear-sky top-ofatmosphere outgoing longwave radiation on atmospheric temperature and water vapor, J. Geophys. Res.-Atmos., 113, D17102, doi:10.1029/2008JD010137, 2008.

ECMWF: ERA-Interim data, European Centre for Medium-Range Weather Forecasts, available at: http://apps.ecmwf.int/datasets/ data/interim-full-daily/levtype=pl/, 2016.
Geier, E. B., Green, R. N., Miler, W. F., Nolan, S. K., and Franklin, C. B.: Clouds and the Earth's Radiant Energy System (CERES) Data Management System Single Satellite Footprint TOA/Surface Fluxes and Clouds (SSF) Collection Document, Release 2, Version 1, NASA Langley Research Center, available at: https://ceres.larc.nasa.gov/documents/collect_guide/pdf/ SSF_CG.pdf, 194 pp., 2003.

GES DISC: AIRS Level 1B data, NASA Goddard Earth Sciences (GES) Data and Information Services Center (DISC), available at: http://airs11.gesdisc.eosdis.nasa.gov/data/Aqua_AIRS_ Level1/AIRIBRAD.005/, 2016.

Goodberlet, M. A., Swift, C. T., and Wilkerson, J. C.: Ocean surface wind-speed measurements of the Special Sensor Microwave Imager (SSM/I), IEEE T. Geosci. Remote Sens., 28, 823-828, doi:10.1109/36.58969, 1990.

Han, Y., Revercomb, H., Cromp, M., Gu, D. G., Johnson, D., Mooney, D., Scott, D., Strow, L., Bingham, G., Borg, L., Chen, Y., DeSlover, D., Esplin, M., Hagan, D., Jin, X., Knuteson, R., Motteler, H., Predina, J., Suwinski, L., Taylor, J., Tobin, D., Tremblay, D., Wang, C. M., Wang, L. H., Wang, L. K., and Zavyalov, V.: Suomi NPP CrIS measurements, sensor data record algorithm, calibration and validation activities, and record data quality, J. Geophys. Res.-Atmos., 118, 12734-12748, doi:10.1002/2013JD020344, 2013.

Hilton, F., Armante, R., August, T., Barnet, C., Bouchard, A., Camy-Peyret, C., Capelle, V., Clarisse, L., Clerbaux, C., Coheur, P.-F., Collard, A., Crevoisier, C., Goldberg, M., Guidard, V., Hurtmans, D., Illingworth, S., Jacquinet-Husson, N., Kerzenmacher, T., Klaes, D., Lavanant, L., Masiello, G., Matricardi, M., Mcnally, A., Newman, S., Pavelin, E., Payan, S., Péquignot, E., Peyridieu, S., Phulpin, T., Remedios, J., Schlüssel, P., Serio, C., Strow, L., Stubenrauc, C., Taylor, J., Tobin, D., Wolf, W., and Zhou, D.: Hyperspectral Earth Observation from IASI: Five Years of Accomplishments, B. Am. Meteor. Soc., 93, 347-370, doi:10.1175/BAMS-D-11-00027.1, 2012.

Huang, X. L., Ramaswamy, V., and Schwarzkopf, M. D.: Quantification of the source of errors in AM2 simulated tropical clearsky outgoing longwave radiation, J. Geophys. Res.-Atmos., 111, D14107, doi:10.1029/2005JD006576, 2006.

Huang, X. L., Yang, W. Z., Loeb, N. G., and Ramasawamy, V.: Spectrally resolved fluxes derived from collocated AIRS and CERES measurements and their application in model evaluation: clear sky over the tropical oceans, J. Geophys. Res.-Atmos., 113, D09110, doi:10.1029/2007JD009219, 2008.

Huang, X. L., Loeb, N. G., and Yang, W. Z.: Spectrally resolved fluxes derived from collocated AIRS and CERES measurements and their application in model evaluation, Part II: cloudy sky and band-by-band cloud radiative forcing over the tropical oceans, J. Geophys. Res.-Atmos., 115, D21101, doi:10.1029/2010JD013932, 2010.

Huang, X. L., Cole, J. N. S., He, F., Potter, G. L., Oreopoulos, L., Lee, D. M., Suarez, M., and Loeb, N. G.: Longwave band-byband cloud radiative effect and its application in GCM evaluation, J. Climate, 26, 450-467, doi:10.1175/JCLI-D-12-00112.1, 2013.

Huang, X. L., Chen, X. H., Potter, G. L., Oreopoulos, L., Cole, J. N. S., Lee, D. M., and Loeb, N. G.: A global climatology of outgoing longwave spectral cloud radiative effect and as- 
sociated effective cloud properties, J. Climate, 27, 7475-7492, doi:10.1175/JCLI-D-13-00663.1, 2014.

Kahn, B. H., Irion, F. W., Dang, V. T., Manning, E. M., Nasiri, S. L., Naud, C. M., Blaisdell, J. M., Schreier, M. M., Yue, Q., Bowman, K. W., Fetzer, E. J., Hulley, G. C., Liou, K. N., Lubin, D., Ou, S. C., Susskind, J., Takano, Y., Tian, B., and Worden, J. R.: The Atmospheric Infrared Sounder version 6 cloud products, Atmos. Chem. Phys., 14, 399-426, doi:10.5194/acp-14-399-2014, 2014.

Kato, S. and Loeb, N. G.: Top-of-atmosphere shortwave broadband observed radiance and estimated irradiance over polar regions from Clouds and the Earth's Radiant Energy System (CERES) instruments on Terra, J. Geophys. Res.-Atmos., 110, D07202, doi:10.1029/2004JD005308, 2005.

Loeb, N. G., Kato, S., Loukachine, K., Manalo-Smith, N., and Doelling, D. R: Angular distribution models for top-ofatmosphere radiative flux estimation from the Clouds and the Earth's Radiant Energy System instrument on the Terra satellite. Part I: Methodology, J. Atmos. Ocean. Tech., 22, 338-351, 2005.

Loeb, N. G., Kato, S., Loukachine, K., Manalo-Smith, N., and Doelling, D. R.: Angular distribution models for top-ofatmosphere radiative flux estimation from the Clouds and the Earth's Radiant Energy System instrument on the Terra satellite. Part II: Validation, J. Atmos. Ocean. Tech., 24, 564-584, 2007.

Minnis, P., Young, D. F., Sun-Mack, S., Heck, P. W., Doelling, D. R., and Trepte, Q.: CERES Cloud Property Retrievals from Imagers on TRMM, Terra, and Aqua, Proc. SPIE, 5235, 37-48, 2004.

Moy, L. A., Knuteson, R. O., Tobin, D. C., Revercomb, H. E., Borg, L. A., and Susskind, J.: Comparison of measured and modeled outgoing longwave radiation for clear-sky ocean and land scenes using coincident CERES and AIRS observations, J. Geophys. Res.-Atmos., 115, D15110, doi:10.1029/2009JD012758, 2010.
O'Carroll, A. G., August, T., Borgne, P. L., and Marsouin, A.: The accuracy of SST retrievals from Metop-A IASI and AVHRR using the EUMETSAT OSI-SAF matchup dataset, Remote Sens. Environ., 126, 184-194, doi:10.1016/j.rse.2012.08.006, 2012.

Susskind, J., Molnar, G., Iredell, L., and Loeb, N. G.: Interannual variability of outgoing longwave radiation as observed by AIRS and CERES, J. Geophys. Res.-Atmos., 117, D23107, doi:10.1029/2012JD017997, 2012.

Strow, L. L., Hannon, S. E., De-Souza Machado, S., Motteler, H. E., and Tobin, D. C.: Validation of the Atmospheric Infrared Sounder radiative transfer algorithm, J. Geophys. Res.-Atmos., 111, D09S06, doi:10.1029/2005JD006146, 2006.

Strow, L. L., Motteler, H., Tobin, D., Revercomb, H., Hannon, S., Buijs, H., Predina, J., Suwinski, L., and Glumb, R.: Spectral calibration and validation of the Cross-track Infrared Sounder (CrIS) on the Suomi NPP satellite, J. Geophys. Res.-Atmos., 118, 12486-12496, doi:10.1002/2013JD020480, 2013.

Wang, L. K., Trenblay, D. A., Han, Y., Esplin, M., Hagan, D. E., Predina, J., Suwinski, L., Jin, X., and Chen, Y.: Geolocation assessment for CrIS sensor data records, J. Geophys. Res.-Atmos., 118, 12690-12704, doi:10.1002/2013jd020376, 2013.

Wielicki, B. A., Barkstrom, B. R., Harrison, E. F., Smith, G. L., and Cooper, J. E.: Clouds and the Earth's radiant energy system (CERES): An Earth observing system experiment, B. Am. Meteor. Soc.,77, 853-868, 1996. 